\title{
Development of digital technologies for the systems of remote mining safety monitoring
}

\author{
Ihor Slashchov ${ }^{1, *}$, Anton Slashchov ${ }^{1}$, Illya Siromaschenko ${ }^{2}$, Volodymyr Kurinnyi ${ }^{3}$, and \\ Maksym Ikonnikov ${ }^{3}$ \\ ${ }^{1}$ Institute of Geotechnical Mechanics named by N. Poljakov of National Academy of Sciences of \\ Ukraine, 49005, Dnipro, Simferopolska Str., 2a, Ukraine \\ ${ }^{2}$ Westphalian University of Applied Sciences, Westfälische Hochschule, 45897, Gelsenkirchen, \\ Neidenburger Str. 43, Germany \\ ${ }^{3}$ National Technical University Dnipro Polytechnic, 49005, Dnipro, Dmytra Yavornytskoho Ave., 19, \\ Ukraine
}

\begin{abstract}
The article is devoted to development of methodology and digital technologies for assessing, forecasting and determining scenarios of geomechanical process evolution. A new digital technology is proposed for remote mining safety monitoring, which integrates a network personnel management system and expert subsystems for decision-making support taking into account geomechanical factors presenting risk of the mine roadway stability loss. Elements of the expert subsystems analyze data in real time, and are used to determine potential risks on basis of criteria and assessments of the production environment state in mines. It is proposed to identify the forecast safety indicators with the help of geomechanical models and by assessing scenarios of the "support-rocks" system stressstrain state evolution. In order the expert assessment of the rock massif and mine roadway stability, integral indicators of emergency potential risk for each geotechnical system elements are specified by values of informative parameters at a certain time point, as well as deviations rates of parameters from the equilibrium point over a period of time. Job safety is provided through the improved effectiveness of personnel interaction and its stricter disciplinary responsibility, as well as by making early decisions on keeping the mine roadways in a trouble-free condition.
\end{abstract}

\section{Introduction}

Studies of statistics of accidents and injuries in the coal mines show that they are caused by geomechanical factors and violations of the Job Safety Rules. Most often, employees are injured or killed as a result of a deliberate violation of the Safety Rules or improper (or no) actions of managers. Sometimes, an employee without sufficient knowledge about requirements of behavior in the underground conditions is allowed to work.

It is obviously that any employer is obliged to ensure safety at each workplace through the observance by the personnel of requirements of the Job Safety Rules in accordance with

*Corresponding author: IMSlashchov@nas.gov.ua 
the current laws and regulations. At the same time, the employee should fulfill the relevant job safety requirements. However, both managers and employees often violate safety precautions, and, in the event of an accident, it is quite difficult to find the true culprit and establish the cause of the accident. Therefore, the problem of improving production discipline and due diligence of the employees is a priority for increasing productivity and ensuring job safety. The problem can be solved only through the improvement of system for controlling complying with the issued orders and the Job Safety Rules.

Today, potential for using digital information technologies in the Ukrainian mining industry for production control and job safety can be very significant. The most effective tool for monitoring job safety in industrial enterprises are modern information systems [13]. At the same time, introduction of the information safety and personnel management systems is constrained by lack of digital technologies, which correspond to specifics and conditions of their use in the mines. This is because of not only necessity to be in line with requirements for the spark- and explosion-proof equipment and impossibility to use standard commercial mobile communications and global positioning systems, but also of lack of software, which meets the needs of mining industry. It should be mentioned that any safety and personnel management system should operate strictly in real time, because if the time constraints are violated, the system completely loses its usefulness for the process of managing production and personnel.

Another reason of the high rate of accidents in Ukrainian mines is difficult mining and geological conditions: minerals are mined at the great depths and in weak and watersaturated rocks causing sudden rock falls, destruction of supports and gobs in the roadways [4, 5]. Injuries reach half of total number of victims. Therefore, methods for forecasting scenarios of evolution of geomechanical processes and creation of digital technologies, which provide proper operation of all of the safety system elements, require further development. In particular, it should be considered promising to improve the following functionalities: remote monitoring of production environment and technological processes; real time informing in case of dangerous situations in the controlled locations; risk and safety analysis; forecast of the rock massif and roadway state; personnel management.

In many countries, new methods for monitoring rock massif and automated systems for collecting and processing primary information were developed and are being introduced into production in order to increase level of the mine safety. For example, the following systems have proven themselves well: digital intelligent systems for seismological monitoring and control (the USA and South Africa), SIWA-2000 (Australia, Germany), CONSPEC $^{\odot}$ (Japan and China), EMAG ${ }^{\odot}$ (Poland), RELIF-2000 ${ }^{\odot}$ (Spain), seismological monitoring system GITS ${ }^{\odot}$, complexes Baikal $^{\odot}$ and DeltaGeon ${ }^{\odot}$ (Russian Federation), experience of the Quanterra ${ }^{\circ}$ system usage (Kazakhstan), etc.

In Ukraine, systems adapted to the needs of mining production, which control air-gas mode in mines, technological parameters and rock stress state were also developed [6-9]. One of the proven and most reliable systems is the UTAS ${ }^{\odot}$ system (Unified Telecommunication Automated System), which includes integrated sensors, data transmission system and electronic-hardware component [9]. Despite the fact that some of the air-gas mode monitoring problems and diagnostics of technological equipment are solved in the $\mathrm{UTAS}^{\odot}$ system, it practically does not apply methods for monitoring and controlling state of the "support-rock massif" geotechnical system. Monitoring data on geomechanical processes are used little due to the diversity, complexity, poor forecastability and insufficient knowledge of the rock behavior in difficult geological conditions.

The purpose of research is development of methodology and digital technologies for assessing, forecasting and determining scenarios of geomechanical process evolution in 
rock massif disturbed by the mining operations.

\section{Methods}

To implement the software components for remote monitoring of mining safety, we used well-known methods of organizing computational processes and constructing software models of information systems.

The development methodology of the expert subsystem is based on the principles of mathematical modeling of the rock massif by the finite element method and includes methods for forecasting the rock massif and roadway support system stability. Finite element mathematical modeling has been widely tested in practice. In research, it is used for assessing the forecast indicators of the rock-massif stress-strain state and possible scenarios of mine roadway stability loss.

The reliability and validity of the results is confirmed by the completeness and correctness of the source data, using proven methods of mathematical modeling of geomechanical processes. To assess the reliability of the safety monitoring system algorithms, computational experiments are confirmed by mine research.

\section{Results and discussion}

\subsection{The concept of constructing of remote control system}

The concept of information system for remote monitoring of mining safety was dictated by the need to solve two main problems.

The first problem is to ensure quality personnel management. Solving of this problem means designing of a basic system for performing the following functions: centralization of information in one computer center; processing of hardware and software data for optimizing production management; control of the manager's order fulfillment by personnel; storage of reporting documents and emergency logs; data transmission and visualization; remote access to personnel management processes (Fig. 1). Solving of this complex of problems facilitates automation of the production management process, but does not perform functions of information support of decision making. The second problem is to support decision making by the experts by providing objective information concerning safety and scenarios of possible changes of the rock massif stress-strain states. In order to support decision-making in the mining industry, two expert subsystems are provided, which perform multivariate analysis of risks and safety levels at the enterprise, as well as provision and analysis of information taken from various normative documents.

Elements of the expert subsystems analyze data in real time, and, if necessary, are used to determine potential risks on basis of criteria and assessments of the state of the production environment in mines including use of mathematical apparatus of fuzzy logic [10-12]. Advantages of the expert subsystems are their ability to forecast geomechanical and gas-dynamic processes in the rock massif and negative consequences caused by these processes in mine roadways (rock falls, destruction of roof supports, floor heaving in the roadways, etc., $[13,14]$ ), as well as accumulation and storage of necessary knowledge in the database. In particular, in order to assess safety of jobs by geomechanical factor, the following data are calculated and stored in the database: local models of the rock massif typical behavior, nomenclature and power characteristics of supports, physical and mechanical properties of rocks and sets of the most common mining and geological conditions of the field development. In contrast to the subjectivity of decisions made by personnel, expert systems process any information according to objective criteria, hence 
improving quality of the data analysis.

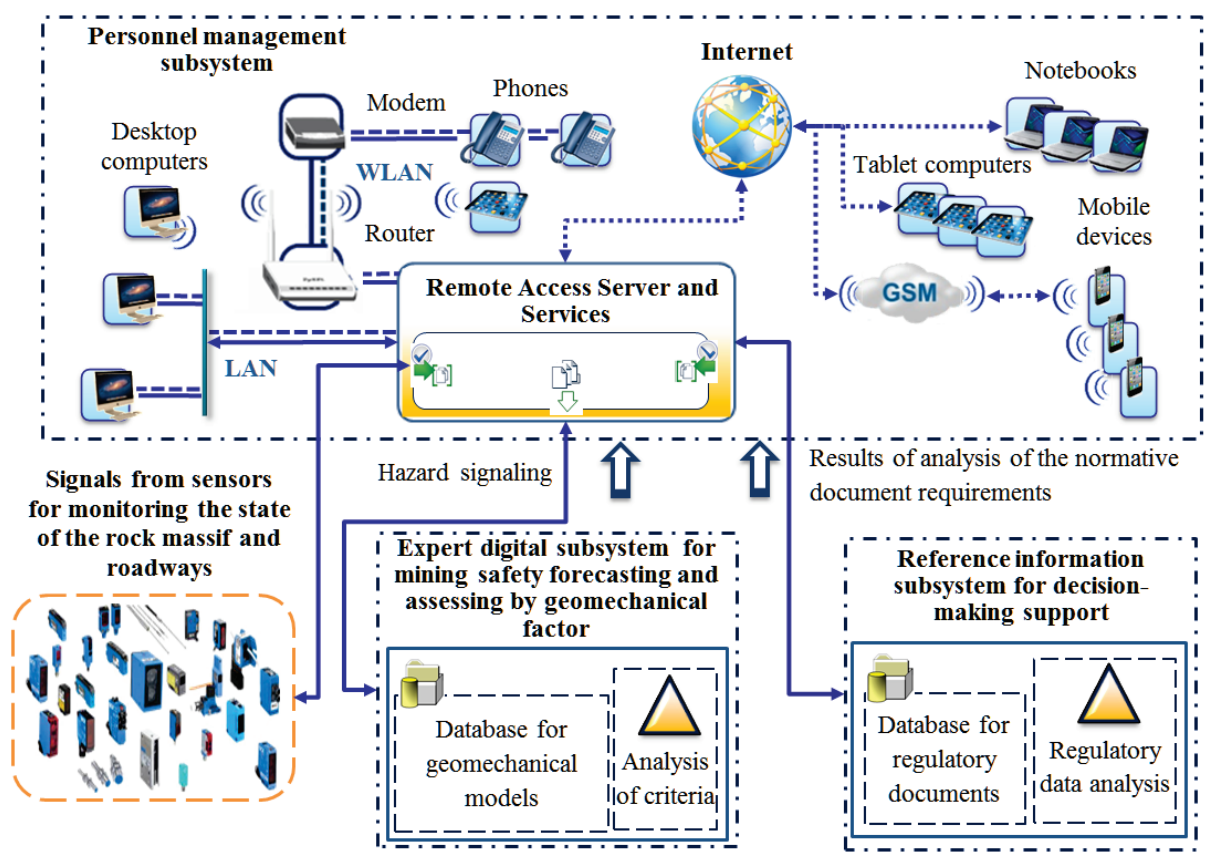

Fig. 1. General layout of the remote safety control system using local and wireless area networks (LAN. WLAN), and Global System for Mobile Communications standard (GSM).

The concept of remote access technologies is interpreted by the NIST Standard SP 80053 [15] of the American National Institute of Standards and Technology as technologies, which provide the user (or the process acting on behalf of the user) with an access (dial-up, broadband and wireless) to the organizational information system and communication via an external network. One of the main features of the remote access technology is the use of the server and Remote Access Services (RAS), which allow the applications to establish remote connections.

An indicator of job safety is also the observance of standards and rules on the basis of industry and other documents [16], which requires the use of reference and information subsystems for processing and analysis of regulatory and technical documentation. Therefore, the system of remote safety monitoring during the mining operations includes: basic client-server subsystem, which performs functions of interaction and personnel management in the enterprise; reference and information subsystem for decision-making support, which provides accumulation of data and analysis of technical documentation; subsystem for analyzing level of mining safety with taking into account geomechanical risk factors for loss of mine roadway stability, which assesses state of the "support-rock massif" system according to the safety criteria and by the fuzzy logic method. This concept of constructing an information system helps to improve efficiency of and job safety at the enterprise.

\subsection{The personnel management subsystem}

The effectiveness of personnel management in the enterprise is characterized by the quality, completeness and timeliness of each employee's performance of their duties. In personnel management methods distinguish indicators of formation, use and development. These indicators characterize the quality of personnel [17-19]. At the same time, enterprise 
managers must decide for themselves, what indicators will be the main based on their own strategic goals and what factors should be used to implement them.

As a result of the research, and with the help of methodology for constructing software models and computational processes, elements of a personnel management system were developed, i.e. a client-server digital information system. The subsystem represents a basis for the remote safety control system and performs the following functions:

- forwarding of written messages from the server to the user and vice versa;

- transferring of photos of the fulfilled works to the server (for monitoring by the managers responsible for the fulfillment of the works);

- transferring of the scaled or divided into parts drawings (geological sections, flowcharts and other graphical information) from the server to the consumer;

- automatic registration of the transmitted information and saving copies in the server database (for further monitoring);

- after any information has been sent, generating an inquiry with a request for a return notification and registration by the server the fact of the message receiving;

- mandatory notification about especially important messages (the signal operates until the user responds to the emergency message);

- automatic adaptation of any displayed information to the size of the client device screen;

- interactive plotting for statistical reports in accordance with performance indicators.

Setting tasks and monitoring their fulfillment are implemented in the system as a cyclic process (Fig. 2).

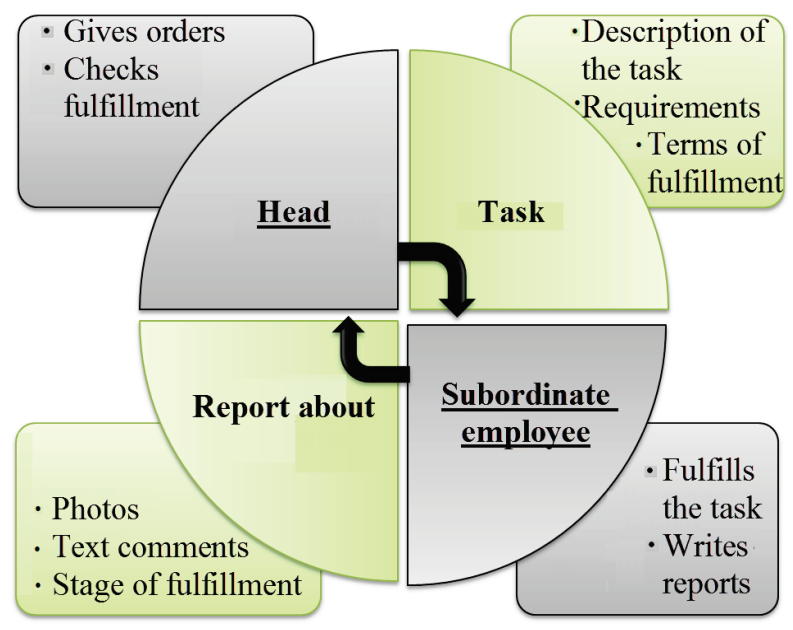

Fig. 2. Organization of the fulfilled work monitoring in the remote control system.

The software package allows transferring the head's instructions and, if necessary, receiving visual report about their fulfillment. Automatic saving of all of the orders and photos of the work results transferred through the system essentially improves quality of the production process control. Having analyzed the orders and photos of the work results, it is possible, if necessary (for example, in case of any accident, or qualification assessment of personnel, or periodic control for the purpose of improving discipline, etc.), to define competence of the employees and quality of their work.

Architecture of the server-client system also includes algorithms for protection against unauthorized access. The system is protected by identification passwords at entering the program and exiting the standby mode of the computer, which makes it possible to control and vary the database access functions for different categories of employees. The employees have access only to the data that are necessary for fulfilling their tasks. In case of expanding 
working functions of system, a code is issued, which extends access to the information.

The visualization program provides a visual representation of statistical reports on performance indicators and other data in graphs, tables, photos and illustrations, which are necessary for better understanding and visualization of information.

The personnel management system improves efficiency of interaction between hierarchical personnel structures. For example, a director of the enterprise, will have been dictating an order, will send it to any group of employees in seconds, and in a few minutes, he will know, which of the employees has not received his order.

It should be noted that safety and personnel management systems show high efficiency worldwide. In particular, in the UK mines, the use of Trolex Ltd and Continental Conveyor Ltd development systems made it possible to escape great explosions and fires over the past decades; the $\mathrm{Cisco}^{\mathcal{O}}$ solutions introduced into production processes of the Dundee Precious Metals mining company for communications between the data processing centers (uniting of people, processes, data and equipment into one network) radically improved safety of miners, increased output by four times and saved 2.5 million US dollars for two years only on communication costs [20].

\subsection{The expert subsystem for forecasting geomechanical processes}

The Institute of Geotechnical Mechanics named by N. Poljakov of National Academy of Sciences of Ukraine does researches on improving mining safety systems using geomechanical models and methods for assessing scenarios of the situation evolution [2124]. It is established that the main obstacle for effective complex use of the mining control systems is inconsistency of the methods for analyzing parameters of the rock massif and roadway monitoring results, as well as insufficient development of methods for assessing an actual situation, safety levels and scenarios of the rock massif stress-strain state changes. Therefore, the main scientific problem in creating the hardware and software architecture of the remote mining safety monitoring system is systematization of a set of parameters for monitoring underground roadways and geological environment disturbed by mining operations, and development of a methodology and synthesis of digital technologies for assessing, forecasting and determining scenarios of geomechanical process evolution.

In order to substantiate indicators of the underground mining operation safety, it is proposed to use a method of mathematical modeling. The purpose of this approach is to determine scenarios of propagation of zones with inelastic deformation and stress changes in the rock massif for cases when different types of supports are used, load on the "supportrock massif" system is increased, and conditions of mineral bedding and rock seam watering are changed.

Under the guidance and with the direct participation of the authors, the geoinformation computing system GEO-RS ${ }^{\odot}$ was developed (Fig. 3). The program is intended for calculating stress-strain state of the rock massif and deformation of the roadways by the finite element method $[6,8,10,13,25]$. To date, the software package has been widely tested for simulation of geomechanical, gas-dynamic and technological processes in mines. Methodological recommendations on the use of the information system are developed, including the basics of its functioning, preparation and deployment, as well as specifics of its application in different mining enterprises. This program is also used as an expert subsystem for forecasting geomechanical processes and helps to improve job safety by making early decisions to keeping the roadways in a trouble-free state.

The expert assessment of the roadway roof and floor state is most effective for combining visual (Fig. 4), instrumental and geophysical control with numerical analysis of the rocks stress-strain state by the finite element method $[1,14,26]$. This approach allows, on the one hand, to verify accuracy of the calculations, determine stage of the deformation 
process, and combine objective data of the instrumental observations with the data obtained by calculation using local models of the rock state.

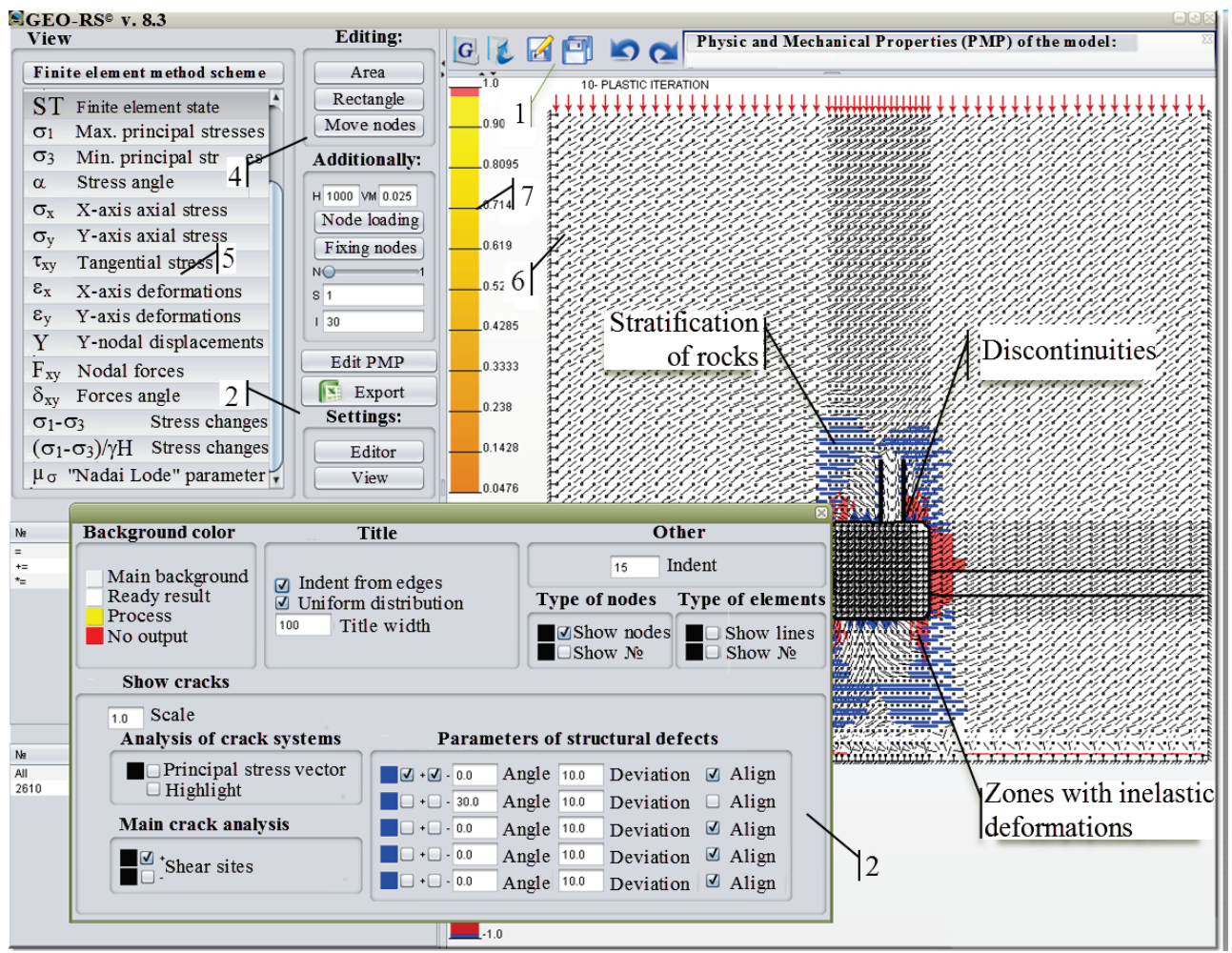

Fig. 3. Main interface of the digital expert subsystem for calculating stability of the rocks and roadways: 1 - menu; 2 - interface for quick access to the program management; 3 - interface for managing data visualization; 4 - interface for adjusting design patterns; 5 - interface for managing the integrated parameters of the model stress-strain state; 6 - window for displaying calculation results; 7 - interface for differentiating ranges of calculated parameters.

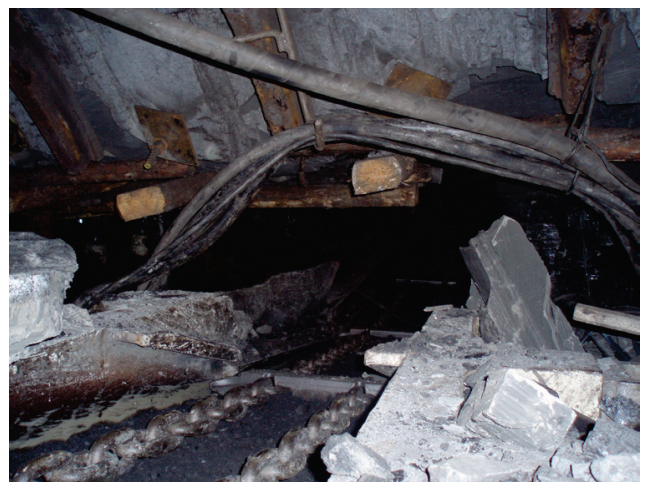

a)

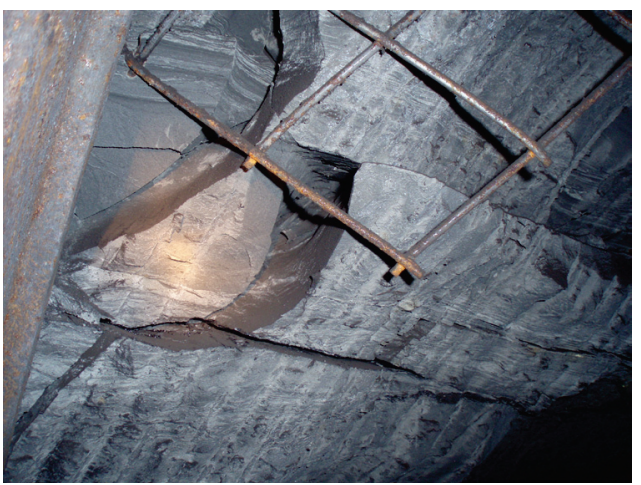

b)

Fig. 4. Identification of rock destruction in the longwall roof (a) and in the roof of preparatory roadway (b) with the help of mine control methods (roadway 535, "Samarska" Mine).

On the other hand, modeling by analytical methods makes it possible to obtain a number of actual and forecasted parameters, which are impossible or extremely difficult to obtain 
by the field research methods. In the first place, these parameters include: zones of inelastic deformations and discontinuity (propagation, volumes, boundaries, rate of change, forecasted values); stresses in the rock massif (maximum principal stresses, rate of change, forecasted values); displacements and forms of the roadway contour deformations (displacements of the roof, floor, sides, rate of change, forecasted values).

The rock massif stress-strain state is assessed by numerical implementation of geomechanical task solution by the finite element method with the GEO-RS ${ }^{\odot}$ software package (Fig. 3). Geomechanical states of the rock massif (including those, which are dangerous for the personnel) are assessed zonally according to the indicated parameters: in the roadway roof - for preventing outfalls, spillages, gobs (geological conditions of the "Samarska" Mine, informative parameter for analysis of risks and safety levels - the forecasted volumes of the destroyed rocks, influencing factor - stress concentration coefficient, as an example, Fig. 5 a); in the roadway floor - for preventing sudden rock rising and heaving (Fig. 5, b). The parameters are calculated with taking into account systems of the roadway supporting used in the mine.

The state of the "support-rock massif" geotechnical system is constantly changing during mining operations, as recorded by personnel and monitoring systems. For assessing parameters for the current geomechanical monitoring of the mine roadways, it is proposed to analyze the deviations of the geotechnical system parameters values from the equilibrium point and the rate of change of this deviation. The potential risk of an emergency is determined for each of the geotechnical system elements (for the mine roadways roof, floor, sides, as an example):

- determination of risk by the values of informative parameters at time $t$

$$
R\left(E^{t}\right)=k_{1}^{t} R\left(E_{1}^{t}\right)+k_{2}^{t} R\left(E_{2}^{t}\right)+k_{3}^{t} R\left(E_{3}^{t}\right)+\ldots+k_{m}^{t} R\left(E_{m}^{t}\right)
$$

- determination of risk by deviations of parameters from the equilibrium point over a period of time $\Delta t$

$$
R\left(E^{\Delta t}\right)=k_{1}^{\Delta t} R\left(E_{1}^{\Delta t}\right)+k_{2}^{\Delta t} R\left(E_{2}^{\Delta t}\right)+k_{3}^{\Delta t} R\left(E_{3}^{\Delta t}\right)+\ldots+k_{n}^{\Delta t} R\left(E_{n}^{\Delta t}\right)
$$

- determination of risk by the rate of deviation of parameters over a period of time $\Delta t$

$$
R\left(E^{v(\Delta t)}\right)=k_{1}^{v(\Delta t)} R\left(E_{1}^{v(\Delta t)}\right)+k_{2}^{v(\Delta t)} R\left(E_{2}^{v(\Delta t)}\right)+k_{3}^{v(\Delta t)} R\left(E_{3}^{v(\Delta t)}\right)+\ldots+k_{k}^{v(\Delta t)} R\left(E_{k}^{v(\Delta t)}\right),
$$

where $R\left(E^{t}\right), R\left(E^{\Delta t}\right), R\left(E^{v(\Delta t)}\right)$ are potential risks of emergency caused in one of the geotechnical system elements, rel. units; $R\left(E_{m}{ }^{t}\right), R\left(E_{n}{ }^{\Delta t}\right) R\left(E_{k}{ }^{v(\Delta t)}\right)$ are risks determined by the values of informative parameters at time $t$, deviations and rates of deviations of the geotechnical system parameters from the equilibrium point for groups of $m, n$ and $k$ influencing factors, respectively, rel. units; $k_{1}{ }^{t}, k_{2}{ }^{t}, \ldots, k_{m}{ }^{t} ; k_{1}{ }^{\Delta t}, k_{2}{ }^{\Delta t}, \ldots, k_{n}{ }^{\Delta t} ; k_{1}{ }^{v(\Delta t)}, k_{2}{ }^{v(\Delta t)}, \ldots$, $k_{k}^{v(\Delta t)}$ are normalized coefficients of influence on the potential risk of individual factors in the group (standardized or normalized in the range from 0 to 1 ).

Also proposed to combine geomechanical factors presenting risk of the mine roadway stability loss by way of integrating the probability estimates of informative parameters of the rock massif and roadway states.

The maximum risk indicator of stability loss of the "support-rock massif" geotechnical system determines the maximum level of risk from all groups of factors:

$$
\max R\left(E^{t}, E^{\Delta t}, E^{v(\Delta t)}\right)=\left\{\begin{array}{c}
k_{1}^{t} R\left(E_{1}^{t}\right), k_{2}^{t} R\left(E_{2}^{t}\right), \ldots, k_{m}^{t} R\left(E_{m}^{t}\right) \\
k_{1}^{\Delta t} R\left(E_{1}^{\Delta t}\right), k_{2}^{\Delta t} R\left(E_{2}^{\Delta t}\right), \ldots, k_{n}^{\Delta t} R\left(E_{n}^{\Delta t}\right) \\
k_{1}^{v(\Delta t)} R\left(E_{1}^{v(\Delta t)}\right), k_{2}^{v(\Delta t)} R\left(E_{2}^{v(\Delta t)}\right), \ldots, k_{k}^{v(\Delta t)} R\left(E_{k}^{v(\Delta t)}\right)
\end{array}\right\} .
$$




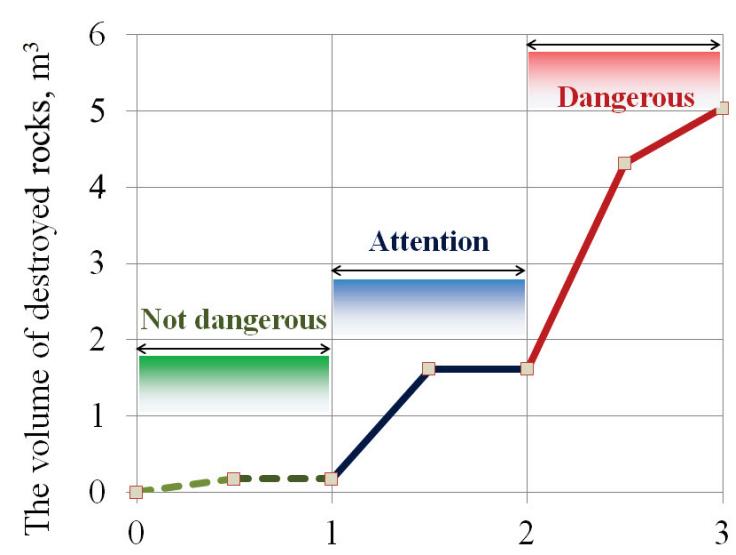

Stress concentration coefficient, rel. units

a)

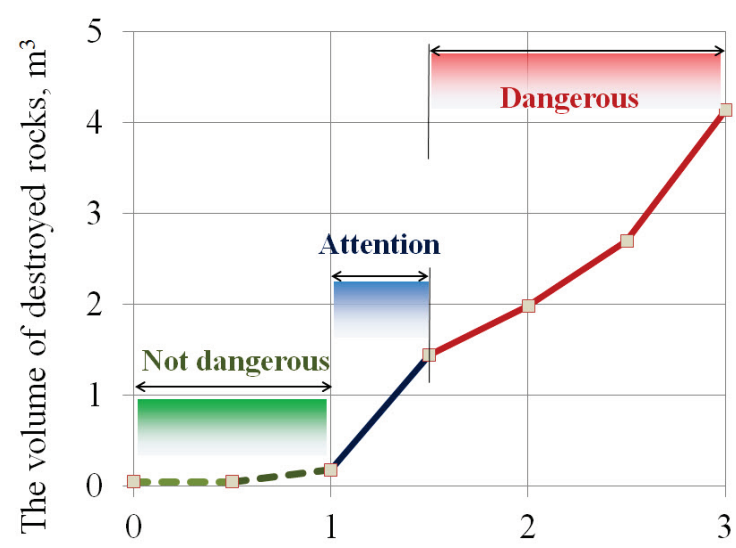

Stress concentration coefficient, rel. units

b)

Fig. 5. An example of the expert assessment of the rock massif dangerous states at increased stresses in zone with bearing pressure (informative parameter - the forecasted volumes of the destroyed rocks): $\mathrm{a}$ - for the roadway roof supported by the roof bolting; $\mathrm{b}$ - for the roadway floor with no additional support.

If the state of a mine working is characterized by a set of parameters, for example, the value of the total displacements of the working contour $u(t)$, then they belong to one of the discrete intervals $\left[\Delta u_{1}=u\left(t_{1}\right)-0\right],\left[\Delta u_{2}=u\left(t_{2}\right)-u\left(t_{1}\right)\right], \ldots,\left[\Delta u_{n}=u\left(t_{n}\right)-u\left(t_{n-1}\right)\right]$. Function (4) in this case will determine the likelihood that no emergency will occur in the time interval $0 \ldots t_{n}$, which consists in the output of the monitoring parameter outside the allowable area.

The second integral indicator determines the risk of the geotechnical system stability loss by the sum of the indicators of individual risk groups:

$$
R_{\Sigma}\left(E^{t}, E^{\Delta t}, E^{v(\Delta t)}\right)=k_{\sum}^{t} \sum_{1}^{m} k_{m}^{t} R\left(E_{m}^{t}\right)+k_{\sum}^{\Delta t} \sum_{1}^{n} k_{n}^{\Delta t} R\left(E_{n}^{\Delta t}\right)+k_{\sum}^{v(\Delta t)} \sum_{1}^{k} k_{k}^{v(\Delta t)} R\left(E_{k}^{v(\Delta t)}\right),
$$

where $k_{\Sigma}{ }^{t}, k_{\Sigma}{ }^{\Delta t}, k_{\Sigma}{ }^{\mathrm{v}(\Delta t)}$ are coefficients for groups of factors (1), (2), (3), normalized in the range from 0 to $1\left(k_{\Sigma}^{t}+k_{\Sigma}^{\Delta t}+k_{\Sigma}^{\mathrm{v}(\Delta t)}=1\right)$. 
The indicator (4) is used to monitor emergency conditions of the "support-rock massif" geotechnical system and determining the dominant risk factor. The indicator (5) is used for a general assessment of the current state of mine safety. When a signal arrives at the dispatcher console or at the input of an automated control system for an object, a recommendation is being developed for the application of technical and technological measures that contribute to the normalization of the geotechnical system.

\section{Conclusions}

Elements of the new digital information system are developed, which provide, effective personnel management at industrial enterprises and control of the rock massif stress-strain state under the influence of the mining operations using network technologies and mobile technical facilities. A digital technology for remote mining safety monitoring integrates the network personnel management subsystem and expert subsystem for decision-making support with taking into account geomechanical factors, criteria and assessments of the rock state, risks of loss of the roadway stability. In order the expert assessment of the rock massif and mine roadway stability, integral indicators of emergency potential risk for each of the geotechnical system elements are specified by the values of informative parameters at a certain point in time, as well as deviations and deviation rates of parameters from the equilibrium point over a period of time. Application of the developed methods and digital technologies helps to improve efficiency and safety of the enterprise. Job safety is ensured by improved efficiency of personnel interaction and disciplinary responsibility, as well as forecast of the rock states, expert assessment of level of the mining safety and timely response to the risks of roadway stability loss.

The authors express their gratitude to the Director of the Institute of Geotechnical Mechanics named by N. Poljakov of National Academy of Sciences of Ukraine, Academician of the National Academy of Sciences of Ukraine, Professor A.F. Bulat for providing technical and informational support for the research.

\section{References}

1. Bulat, A.F. and Slashchov, I.N. (2012), Development of computer systems mathematical modeling geomechanical processes. Geoteh. meh., 99, 16-27

2. O. Krukovskyi, V. Krukovska. Numerical simulation of the stress state of the layered gas-bearing rocks in the bottom of mine working. E3S Web of Conferences, International Conference Essays of Mining Science and Practice, 109 (2019). https://doi.org/10.1051/e3sconf/201910900043

3. Pohlmann N., Sparenberg M., Siromaschenko I., Kilden K. (2014) Secure Communication and Digital Sovereignty in Europe. In: Reimer H., Pohlmann N., Schneider W. (eds) ISSE 2014 Securing Electronic Business Processes. Springer Vieweg, Wiesbaden. https://doi.org/10.1007/978-3-658-06708-3_12

4. Anciferov, A.V. [et al.] (2010). Heomekhanichnyy mōnitorynh pidzemnykh heotekhnichnykh system. Donetsk: Noulidzh

5. O. Voloshyn, O. Riabtsev. Some important aspects of rock mechanics and geomechanics. E3S Web of Conferences, International Conference Essays of Mining Science and Practice, 109 (2019). https://doi.org/10.1051/e3sconf/201910900114

6. Shevchenko, V.G., Slashchov, A.I. (2016). Validation of parameters and design of information system on the underground mining job safety with taking into account geomechanical factors. Geoteh. meh., 128, 70-78 
7. Shulga, Yu.I., Zdanovskiy, V.G., Krivtsov, N.V., Ignatovich, N.V. (2010). Mines safety systems of Ukraine, their capabilities and prospects. Problemy okhorony pratsi $v$ Ukrayini, 18, 3-11

8. Slashchov, I.N., Shevchenko, V.G., Slashchov, A.I. (2013). Optimized information system for on-line predicting of geomechanical process behavior and ensuring proper decision-making on the mine safety. Geoteh. meh., 112, 129-144

9. Derdin, O. (2009). The "UTAS" system is a presumption of non-alternativeism. Everything about labor protection, 10, 2-9

10. Shevchenko, V.G., Slashchov, A.I. (2018). Information systems for underground mining safety and productivity. Kiev: Naukova Dumka

11. V. Shevchenko, A. Slashchov. Justification of the basic algorithms of the mine safety information system. E3S Web of Conferences, International Conference Essays of Mining Science and Practice, 109 (2019). https://doi.org/10.1051/e3sconf/ 201910900086

12. A. Slashchov, O. Yalanskyi. Substantiation of fuzzy logic algorithms for control problems of a geotechnical systems. E3S Web of Conferences, International Conference Essays of Mining Science and Practice, 109 (2019). https://doi.org/10.1051/e3sconf/ 201910900091

13. Slashchov, I.M. (2019). Basic preconditions for development of mine safety systems by using production environment remote control methods. International independent scientific journal, 3(1), 40-48

14. Slashchov, I.M., Shevchenko, V.G, Kurinnyi, V.P., Slashchova, O.A., Yalanskyi, O.A. (2019). Forecast of potentially dangerous rock pressure manifestations in the mine roadways by using information technology and radiometric control methods. Mining of Mineral Deposits, 13(4), 9-17

15. NIST Special Publication 800-53A Revision 5. Security and Privacy Controls for Federal Information Systems and Organizations. National Institute of Standards and Technology (Retrieved July 24, 2019)

16. Amy DelPo, The Performance Appraisal Handbook: Legal \& Practical Rules for Managers, NOLO: 2nd edition (2007)

17. Romanova, T.I., Vinichuk, T.G. (2008). Otsenka effektivnosti ispol'zovaniya trudovogo potentsiala $i$ sistemy upravleniya personalom predpriyatiya. Tomsk: Tomsk State University of Architecture and Civil Engineering

18. Dave Ulrich, Measuring Human Resources: An Overview of Practice and a Prescription for Results, Human Resource Management, 36(4), 303-320 (1997)

19. David Parmenter, Key Performance Indicators (KPI) Fourth Edition: Developing, Implementing, and Using Winning KPIs, Wiley: 4 edition (2019). https://doi.org/10.1002/9781119620785

20. Solution Overview Cisco Unified Wireless Network, available at: https://www.cisco.com/ c/en/us/ solutions/enterprise/design-zone-industry-solutions/ index.html. (Accessed 7 January 2017)

21. Bulat, A.F., Slashchov, I.M., Slashchova, O.A. (2017), Evaluation methods of interconnected geomechanical and gas dynamic processes in the rock massif for the systems of working medium control in the mines, Geoteh. meh., 134, 3-21

22. Slashchov, A.I. (2016), Justification of the parameters of the information system assuring the underground mining safety, Naukovyi Visnyk Natsionalnoho Hirnychoho Universytetu, 1, 77-85

23. O. Slashchova, I. Slashchov, I. Sapunova. Specific solution of problem of water filtering in the rocks by the finite element method. E3S Web of Conferences, International Conference Essays of Mining Science and Practice, 109 (2019). https://doi.org/10.1051/e3sconf/201910900093 
24. I. Slashchov. Estimation of fracture systems parameters in rock massif by the finite element method. E3S Web of Conferences, International Conference Essays of Mining Science and Practice, 109 (2019). https://doi.org/10.1051/e3sconf/201910900094

25. Slashchov, I.M. (2019), Stress-strain state of rock massif when using combined support systems in preparatory mine workings, Danish Scientific Journal, 22(1), 57-64

26. O. Slashchova. Water effect on the rocks and mine roadways stability. E3S Web of Conferences, International Conference Essays of Mining Science and Practice, 109 (2019). https://doi.org/10.1051/e3sconf/201910900092 